\title{
INDICADORES DO TRANSPORTE DE CARGA: UM ESTUDO DE CASO NA REGIÃO DOS CAMPOS GERAIS - PR
}

\author{
PICININ, Claudia Tania ${ }^{1}$ \\ KOVALESKI, João Luiz ${ }^{2}$ \\ PEDROSO, Bruno ${ }^{3}$
}

Recebido em: 2011-04-05

Aprovado em: 2011-10-24

ISSUE DOI: $10.3738 / 1982.2278 .552$

\begin{abstract}
RESUMO: Os indicadores do transporte de carga, como importação e exportação, podem ser expressivos em uma região, devido ao entroncamento logístico presente. Este trabalho tem por objetivo efetuar um levantamento dos indicadores do transporte de carga (importação e exportação) na região dos Campos Gerais PR. Os dados empíricos de caráter secundários foram obtidos através de informações disponíveis de forma online em órgãos federais ligados como o Ministério do desenvolvimento, Instituto Brasileiro de Geografia e Estatística, com foco na região estudada. A teoria abordada converge nos modais de transporte, enfatizando suas características e custos. A região dos Campos Gerais apresenta exportações significativas, representando $41 \%$ do volume do Estado em 2004. No entroncamento logístico da região dos Campos Gerais está centrado nos modais rodo-ferroviário, centralizando um grande volume das cargas na região.
\end{abstract}

Palavras-chave: Logística. Transporte de carga. Modais de transporte.

SUMMARY: The load transportation indicators, like import and export, can be expressive in a region, due to the present logistic junction. This work has for goal make a transportation indicators rising of load (import and export) in the region of Campos Gerais-PR. The empiric data of secondary character were obtained through available information of online form in linked federal organs as the development Department, Brazilian Institute of Geography and Statistical, with focus in the studied region. The boarded theory converges in the modal of transportation, emphasizing their characteristic and costs. The region of the Campos Gerais presents significant exports, representing $41 \%$ of the volume of the State in 2004. In the logistic junction of the region of the Campos Gerais is centered in the modal rake-railroad, centralizing a loads great volume in the region.

Key-words: Logistics. Load transportation. Modal of transportation.

\section{INTRODUÇÃOO}

Empresas de atuação no ramo logístico, assim como diversos outros segmentos tiveram um desenvolvimento rápido na área empresarial e estão adquirindo um caráter estrutural na área de gerência.

O gerenciamento do tempo correspondente ao despacho aduaneiro para expedição para entrada no país precisa ser cuidadosamente avaliado e, principalmente, evitado a ociosidade de tempo para desempenho das atividades. Um planejamento detalhado das ações

\footnotetext{
${ }^{1}$ Mestre em Engenharia de Produção pela Universidade Tecnológica Federal do Paraná

${ }^{2}$ Doutor em Instrumentação Industrial pela Université Joseph Fourier, Grenoble - França

${ }^{3}$ Doutorando em Educação Física pela Universidade Estadual de Campinas
} 
possíveis ou indicadas poderiam evitar certos imprevistos e reduzir as probabilidades de atrasos de envio de cargas ou pagamento de armazenagem.

Os modos utilizados para se efetuar um transporte podem ser os mais variados dependendo do tipo de carga, localização da empresa produtora, disponibilidade de recursos para a realização do transporte como, por exemplo, rodovias, ferrovias, aeroportos e portos, bem como diversos outros fatores que podem influenciar direta e indiretamente esta prática.

Segundo Damaria (2004), a intermodalidade no transporte de carga utiliza a integração de diferentes modalidades, tendo como principal objetivo o ganho de eficiência. $\mathrm{O}$ transporte intermodal precisa obrigatoriamente de um conhecimento de transporte para cada embarque em modal diferente sob diferentes responsabilidades, já o transporte multimodal exige um único conhecimento de transporte sob a responsabilidade de uma pessoa jurídica.

Para Rodrigues (2003, p. 31) estes modais podem ser subdivididos em rodoviário, ferroviário, Fluvial/Lacustre, Marítimo, Aquaviário, Aéreo, Dutoviário. O transporte rodoviário, mesmo representando em alguns casos custo elevado para o transportador, abrange a maior parte do território Brasileiro. O transporte ferroviário não tem flexibilidade de percurso, ficando restrito a um único caminho, não é rápido como o transporte rodoviário, porém apresenta custo sensivelmente menor. O transporte rodoviário se diferencia do ferroviário por alimentar rotas de curta distância, produtos acabados e semi-acabados.

Quando se utiliza a tecnologia como instrumento de apoio para o alcance dos objetivos organizacionais, faz-se necessário o uso da gestão da tecnologia que, segundo Vasconcelos (1992), seria o uso de técnicas de administração com a finalidade de maximizar o potencial desta tecnologia. Já a transferência de tecnologia pode ser compreendida como o processo pelo qual as empresas são capazes de compreender, introduzir, adotar e dominar o conhecimento de determinados processos ou equipamentos. Para que ocorra a transferência, é necessário no mínimo duas partes, uma detentora da tecnologia e a outra a contratante da tecnologia ou equipamentos.

Este estudo visa efetuar um levantamento dos indicadores do transporte de carga (importação e exportação) na região dos Campos Gerais - PR.

\section{REFERENCIAL TEÓRICO}

\subsection{INTERMODALIDADE E MODAIS DE TRANSPORTE}

Para Betarelli Júnio; Bastos; Perobelli (2011), sob a ótica econômica, o transporte é um setor de serviços intermediário, utilizado para transações de compra e venda de produtos 
intermediários. Assim, as transações físicas (nacional e internacional) demandam algum transporte (caminhão, trem, avião, navio, navegação fluvial, etc).

A intermodalidade no transporte de carga utiliza a integração de diferentes modalidades, tendo como principal objetivo o ganho de eficiência. De acordo com o mesmo, o transporte intermodal precisa obrigatoriamente de um conhecimento de transporte para cada embarque em modal diferente sob diferentes responsabilidades, já o transporte multimodal exige um único conhecimento de transporte sob a responsabilidade de uma pessoa jurídica. No Brasil o intermodalismo é utilizado na cabotagem, e os resultados são quedas de até $20 \%$ nos custos (DAMARIA, 2004).

Os modos utilizados para se efetuar um transporte podem ser os mais variados dependendo do tipo de carga, localização da empresa produtora, disponibilidade de recursos para a realização do transporte como, por exemplo, rodovias, ferrovias, aeroportos e portos, bem como diversos outros fatores que podem influenciar direta e indiretamente esta prática.

De acordo com (RODRIGUES, 2003), estes modais podem ser subdivididos em:

- Rodoviário: Neste modal a carga é transportada pelas rodovias, em caminhões (veículos fixos); carretas (veículos articulados); trailers, plataformas (para transporte de containeres), entre outros;

- Ferroviário: Normalmente une países limítrofes. Esse transporte não tem flexibilidade de percurso, ficando restrito a um único caminho, não é rápido como o transporte rodoviário, porém apresenta custo sensivelmente menor. A carga é transportada por ferrovias, em vagões fechados, plataformas etc.;

- Fluvial/Lacustre: O transporte fluvial e o lacustre são realizados em embarcações, porém o primeiro ocorre através de rios, e o segundo em lagos ou lagoas. Esse tipo de transporte possui utilização muito pequena no Brasil, se comparado ao potencial de sua utilização. Neste modal são utilizadas as balsas, chatas e pequenos barcos, assim como navios de médio porte;

- Marítimo: Realizados por navios a motor, a carga é transportada em embarcações, pelos mares e oceanos. Damaria (2004) afirma que os navios cargueiros apresentam-se em várias formas: os convencionais, de carga geral, os de carga frigorífica, graneleiros, navios-tanque, roll-on roll-of, porta-conteineres, entre outros, adaptandose aos mais variados tipos de carga;

- Aquaviário: Abrange em uma só definição os modais marítimo e hidroviário. Segundo Damaria (2004), no Brasil é permitido o estilo de Cabotagem, navegação interior e navegação de longo curso; 
- Aéreo: Esse tipo de transporte envolve diversos países, devido à alta velocidade no deslocamento. São utilizados aviões para o transporte das cargas, através do espaço aéreo.

- Dutoviário: Segundo Damaria (2004), esse modal de transporte se utiliza de dutos para o transporte das mercadorias. Pelas próprias condições físicas do meio, os principais produtos que se utilizam desse modal são os derivados de petróleo, refinados de grãos (óleo), gases e álcool, em sua maioria.

Pode-se destacar de que no Brasil, são utilizados todos estes tipos de transporte, tanto para o transporte nacional quanto para o transporte internacional, porém em âmbito nacional o rodoviário é o mais utilizado. O transporte rodoviário se diferencia do ferroviário por alimentar rotas de curta distância, produtos acabados e semi-acabados. Ballou (1993) afirma que a diferença básica entre o modal ferroviário e o rodoviário quanto a sua forma de atuação, é que caminhões são capazes de manipular menor variedade de cargas, devido a restrições de segurança (quanto a tamanho e peso do produto transportado). Além disso, os caminhões oferecem maior agilidade na entrega de cargas parceladas.

Para Damaria (2004), a escolha do modal a ser utilizado na distribuição internacional das mercadorias é ponto essencial, por isso é de suma importância conhecer a cada um deles detalhadamente para criação e desenvolvimento de uma logística adequada. Para a autora, principalmente no comércio exterior, que em geral contempla maiores distâncias a serem percorridas e a participação de detalhes adicionais ao transporte interno, a escolha do modo de transporte a ser utilizado não deve ser baseada exclusivamente na comparação entre tarifas de frete, mas sim em análise mais ampla, que considere as variáveis que estão ligadas a cada modalidade.

Quanto ao modal aéreo, no Brasil, com o passar do tempo, o transporte aéreo registrou a sua maior significância no Brasil, na área de traslado de passageiros devido à maior acessibilidade e à facilidade em atingir distâncias maiores em menor tempo. (BARROS et al., 2010).

Nesse contexto de competitividade, muitas empresas de transporte aéreo, precisaram se reorganizar para superar a redução do tráfego e o aumento dos custos gerados por novas medidas de segurança, posterior ao ataque de 11 de setembro de 2001, que ocasionou uma crise (CORREIA; MELLO; MEZA, 2011). Isso gerou uma nova forma de prestação de serviços.

Todos os modais de transporte utilizam-se de terminais para o deslocamento das cargas. Os terminais são inevitavelmente a origem ou destino do tráfego, e, em alguns casos, o ponto onde a carga necessite de serviços como consolidação/desconsolidação para a 
distribuição da carga. Desta forma, eles podem ser considerados uma união de facilidades, onde se origina ou conclui o processo de transporte.

Na visão de Haddad (2006), os impactos dos investimentos no setor de transportes podem ser distintos para cada região. Geralmente, os investimentos refletem na produtividade sistêmica e em melhorias de infraestrutura, que podem gerar economia de escala e de acessibilidade. Esses fatores, ainda poderão gerar maior competitividade regional.

Para este estudo, serão detalhados os modais de transporte rodoviário e ferroviário, por estarem diretamente ligados ao estudo de caso avaliado: análise das importações e exportações da região do Campos Gerias.

\subsubsection{MODAL FERROVIÁRIO}

Esse modal de transporte tem predominado sobre os demais no nosso atendimento ao mercado interno ao longo das últimas décadas, devendo continuar assim ainda por mais algum tempo (KEEDI 2003). Como se pode observar, o transporte rodoviário possui ainda uma longa vida útil no Brasil, pois mesmo ele possuindo um custo consideravelmente alto se comparado com o ferroviário, por exemplo, leva vantagem pela estrutura que o país lhe oferece, em termos de malhas viárias existentes.

"A rápida ampliação da infra-estrutura rodoviária explica-se pelo menor custo de implantação por quilômetro e menor prazo de manutenção do que o correspondente na malha ferroviária" (RODRIGUES, 2003, p. 49). Um dos principais motivos para o desenvolvimento da malha rodoviária é o menor tempo para construção e manutenção, sendo incentivada a escolha deste modal pelos governantes, principalmente no período de Juscelino Kubitschek.

Para Ballou (2001) o serviço de transporte rodoviário comporta produtos semiacabados e acabados, para extensões de 646 milhas para cargas incompletas (LTL - less-thantruck load) e de 274 milhas para cargas completas (TL - truck load).

Para Damaria (2004), o transporte rodoviário é o mais flexível e o mais ágil no acesso às cargas. Elas são transportadas em espaços reservados diretamente com os transportadores, o que pode ser feito juntamente com outras cargas ou isoladamente, quando a carga for suficiente para o espaço total do veículo.

Esse modal apresenta uma vantagem perante o modal ferroviário e o aéreo, pois os serviços porta a porta não são interrompidos por cargas e descargas entre a origem e o destino, além da sua frequência de realização, disponibilidade, velocidade e conveniência. Além dessas características próprias, o modal rodoviário se diferencia do ferroviário em outros 
aspectos, como exemplo, o transporte pode ser comum, privado ou ainda contratado, através de contrato de um transportador que atenda as necessidades de forma particular de um embarcador.

O transporte rodoviário é bastante difundido pela estrutura que lhes é oferecida e pela praticidade com relação ao desdobramento do percurso. De acordo com (RODRIGUES, 2003, p. 51), "o transporte rodoviário é um dos mais simples e eficientes dentre seus pares. Sua única exigência é existirem rodovias".

O transporte rodoviário tem uma característica única, que o diferencia de todos os demais modais, que é a sua capacidade de tráfego por qualquer via. Ele não se fixa a trajetos fixos ou a rotas rígidas, tendo a capacidade de transitar por qualquer lugar, apresentando uma flexibilidade ímpar. Isso lhe dá uma vantagem extraordinária na disputa pela carga com os demais modais (KEEDI, 2003).

A flexibilidade oferecida pelo transporte rodoviário sem dúvida é um dos principais diferenciais que o mantêm a frente dos demais modais, sendo assim, há hoje no país uma frota considerável de caminhões que executam esse tipo de serviço, tanto para cargas fechadas, quanto para cargas fracionadas.

Os veículos utilizados no transporte rodoviário são classificados de acordo com sua capacidade de carga, quantidade e distância entre eixos. Porém, para facilitar a compreensão, vamos classificá-los pelas finalidades a que se destinam (RODRIGUES, 2003):

Assim, os caminhões podem ser divididos e destinados cada um o seu tipo de carga pertinente, facilitando as empresas que precisam contratar algum serviço de frete específico, bem como órgãos fiscalizadores do governo. A simplicidade de funcionamento do transporte rodoviário é o seu ponto forte, pois não apresenta qualquer dificuldade e está sempre disponível para embarques urgentes. Esse modal confere maior flexibilidade, oferecendo algumas vantagens (DAMARIA, 2004).

A movimentação das cargas através das ferrovias oferece diversos benefícios especiais ao embarcador, seja no transporte a granel, carvão ou grãos, produtos refrigerados ou automóveis, que exigem equipamentos especiais para transporte.

\subsubsection{MODAL RODOVIÁRIO}

Segundo Ballou (2001), existem duas formas legais para o serviço ferroviário, sendo o de transportador comum ou privado. Para os serviços privados, o transportador vende o transporte a todos os embarcadores, sendo os serviços quitados pelas regulamentações econômicas e de segurança das agências governamentais. Já o transporte privado é adquirido 
pelo embarcador, com a finalidade de atender apenas ao proprietário. Devido ao escopo limitado do transportador privado, a movimentação ferroviária é do tipo comum.

De acordo com Damaria (2004), o modal ferroviário liga normalmente países limítrofes. Não tem flexibilidade de percurso, por ficar restrito a um único caminho, e não é tão ágil quanto o transporte rodoviário. A participação do transporte ferroviário do Brasil com os países latino-americanos é ainda pequena, sendo a diferença de bitola um dos maiores problemas.

Para esse modal são comuns as cargas completas (CL - carload), onde a carga se aproxima da capacidade máxima . Já as cargas incompletas (LCL - less-than-carload) não são muito usadas devido a taxa particular que é aplicada a cada carga.

A logística conta com os efeitos trade off e lead time. O trade off pode ser entendido como uma escolha ou concessão de negócio, já o lead time é o tempo de processamento de um pedido até a entrega ao cliente. Segundo Christopher (2002), o trade off pode ser avaliado sob o ponto de vista de seu impacto sobre os custos totais e sobre a receita das vendas. Pode se possível um trade off com aumento dos custos totais, desde que a receita de vendas também aumente. Se a diferença entre a receita e os custos for maior que a anterior, então o trade off está proporcionando melhorias na eficiência de custos.

\subsection{EXPORTAÇÕES E IMPORTAÇÕES}

De 2001-2007, o Brasil foi marcado por intenso crescimento na sua balança comercial, partindo de um déficit em 2000 para um superávit em 2007. A variação do superávit foi de 2,6 bilhões de dólares em 2001 para 40 bilhões de dólares em 2007. Nesse período, houve aumento tanto das importações quanto das exportações. A economia nacional não acompanhou o desenvolvimento do setor de importações e exportações (CUNHA; PAULA; FEITOSA, 2009).

Analisando o contexto das exportações e importações, nota-se que de um lado estão as políticas governamentais de abertura econômica e, de outro, forcas independentes comandadas pelo progresso tecnológico. Os avanços e alterações provenientes deste setor oferecem reduções de custos em transações e interligam regiões a mercados mundiais, por meio de redes.

Através dessas redes originadas, os produtos de uma empresa ou até mesmo uma pequena região abrangem uma extensão territorial maior. Assim, a exportação representa uma diversificação de mercado, mantendo a empresa menos sensível a flutuações do mercado interno. Para o Banco do Brasil (2006, p. 9) "significa como conseqüência da conquista de 
novos mercados, maior receita e emprego. Significa, para o governo, maior entrada de divisas [...]". Neste aspecto, a exportação é tudo o que sai das fronteiras e importação é tudo o que atravessa as fronteiras com destino ao interior do país.

Todo o processo de comércio exterior Brasileiro segue uma determinada estrutura, representada na Figura 1:

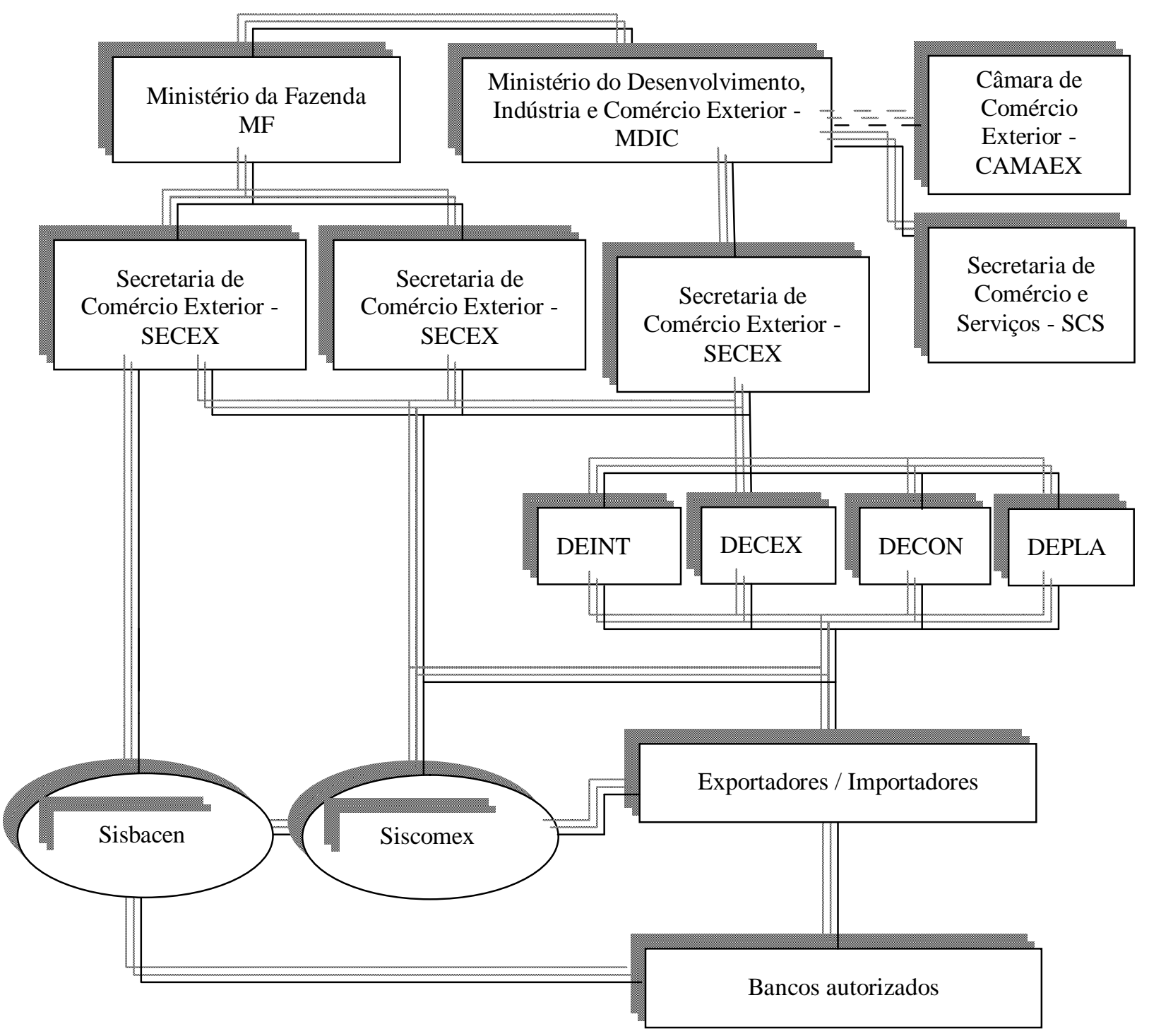

Figura 1 - Sistema de comércio exterior Brasileiro Fonte: Universidade corporativa Banco do Brasil

$\mathrm{Na}$ estrutura que compõe o sistema de comercio exterior Brasileiro, O Banco Central do Brasil (BACEN) mantém o registro dos contatos de Câmbio, fornecendo a Receita Federal informações pertinentes a contratos efetuados por intermédio dos bancos autorizados a operar no câmbio. A Receita Federal Brasileira (RFB) fiscaliza a movimentação de bens no país, tanto na exportação quanto na importação. As principais atividades correspondem a despacho aduaneiro, recolhimento de tributos, fiscalização do fluxo financeiro e manutenção de recursos no exterior. 
Além da estrutura do comércio exterior brasileiro, a empresa opta por uma sequência interna de decisões quanto a sua forma de entrada no comércio internacional, conforme demonstrado na Figura 2:

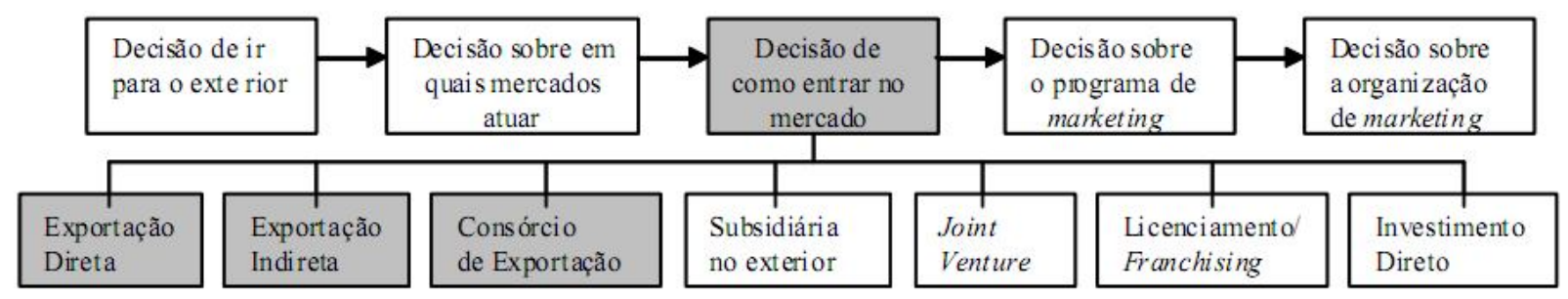

Figura 2: principais decisões e formas de entrada no mercado internacional

Fonte: (Lima et al, 2008, p. 5)

Após as decisões internas quanto às formas de exportar, a empresa necessita de adequação quanto às normas da Secretaria de Comércio Exterior (SECEX). A SECEX define as normas, incluindo procedimentos administrativos e comerciais, juntamente ao Departamento de Negociações internacionais (Deint), Departamento de Operações de Comércio Exterior (Decex), Departamento de Defesa Comercial (Decom) e Departamento de Planejamento e Desenvolvimento do Comércio (Depla). O Deint desenvolve atividades junto a organismos internacionais, o Decex realiza o licenciamento e controle das operações de comércio exterior, o Decom efetua funções de defesa comercial, garantindo que a entrada de produtos no país ocorra seguindo a legislação de comércio e o Depla formula propostas de planejamento de ações governamentais e acompanha a execução das políticas e programas que envolvem o comércio exterior.

O controle das operações de comércio exterior e câmbio fazem parte de um processo de integração realizados pelo Sistema Integrado de Comércio Exterior (SISCOMEX) e Sistema de Informações do Banco Central (SISBACEN).

O Siscomex é um instrumento administrativo que integra as atividades de registro, acompanhamento e controle das operações de comércio exterior. Tem a função de analisar essas atividades, verificando índices como preço, prazo, comissão de agentes, condição e forma de pagamento. A verificação é realizada com a finalidade de permitir que autoridades governamentais possam acompanhar e fiscalizar o processo (UNIVERSIDADE CORPORATIVA BANCO DO BRASIL, 2006).

O Sisbacen é um sistema informatizado que permite o acompanhamento diário das operações de câmbio realizada pelos banco e outros agentes autorizados. Esse sistema pode ser consultado também por importadores, exportadores, universidades e ministérios (UNIVERSIDADE CORPORATIVA BANCO DO BRASIL, 2006). 
O processo de exportação segue uma seqüência ordenada de ações, representadas pela

Figura 3:

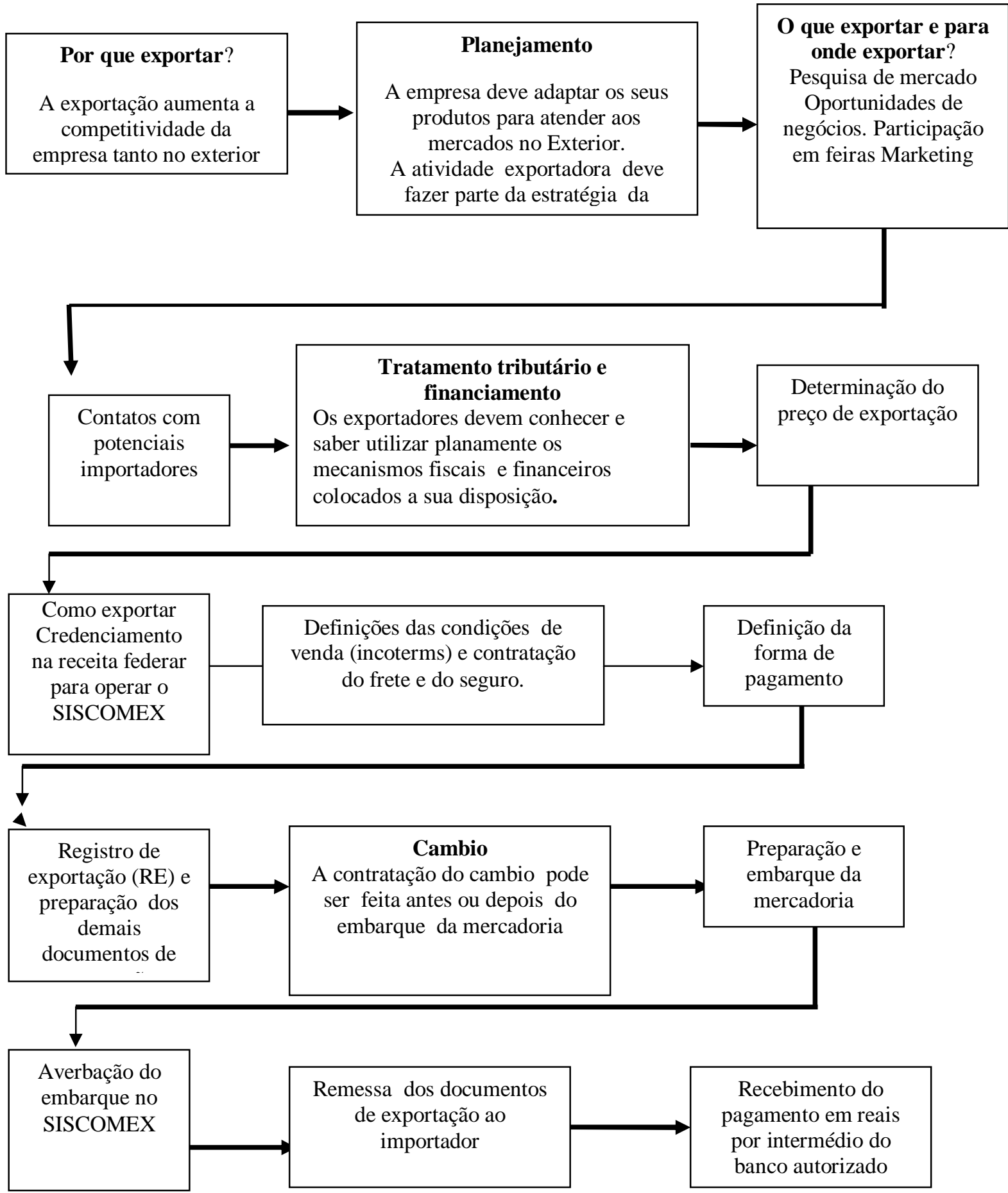

Figura 3 - Fluxograma de exportação

Fonte: Universidade Corporativa Banco do Brasil

Algumas das etapas poderão ter a sua ordem ser alterada em função de cada empresa, mas os itens serão basicamente os mesmos.

O comércio internacional é regulado por direitos e deveres entre as partes que, por sua vez indicam em que local e momento termina a responsabilidade do vendedor e do 
comprador. Esses deveres cabem tanto na importação quanto na exportação (UNIVERSIDADE CORPORATIVA BANCO DO BRASIL, 2006).

São 13 os termos utilizados no processo de comércio exterior. Esses termos são chamados de incoterms.

Os termos a seguir serão especificados conforme a Universidade Corporativa Banco do Brasil (2006). São termos utilizados no transporte marítimo, fluvial ou lacustre:

- FOB (free on board - livre a bordo): O vendedor encerra suas obrigações quando a mercadoria transpõe a amurada do navio no porto de embarque indicado e, a partir daquele momento, o comprador assume todas as responsabilidades quanto a perdas e danos, sendo o vendedor responsável pelo desembaraço da mercadoria para exportação.

Os incoterms que expressam que o importador responsabiliza-se pelo frete, seguros internacionais e desembaraço da mercadoria no porto de desembarque são:

- FAS (free alongside ship - livre no constado do navio): Vendedor encerra suas obrigações no momento em que a mercadoria é colocada ao lado do navio transportador, no cais ou em embarcações utilizadas para carregamento, no porto de embarque designado, entregando ao comprador com o desembaraço realizado. Posteriormente, o comprador assume todos os riscos e custos com carregamento, pagamento de frete e seguro e demais despesas;

- CFR (cost and freight - custo e frete): O vendedor é o responsável pelo pagamento dos custos necessários para colocar a mercadoria a bordo do navio, pagamento do frete até o porto de destino designado e desembaraço, sendo que os riscos de perda ou dano da mercadoria, bem como quaisquer outros custos adicionais são transferidos do vendedor para o comprador no momento em há que a mercadoria cruze a murada do navio;

- CIF (cost, insurance and freigth - custo, seguro e frete): A responsabilidade sobre a mercadoria é transferida do vendedor para o comprador no momento da transposição da amurada do navio no porto de embarque, sendo o vendedor responsável pelo pagamento dos custos e do frete. O vendedor deverá quitar o desembaraço das mercadorias para exportação, contratar e pagar o prêmio de seguro do transporte principal e seguro pago com cobertura mínima;

- DES (delivered ex-ship - entregue no navio): O vendedor deve colocar a mercadoria à disposição do comprador, à bordo do navio, não desembaraçada para a importação, no porto de destino designado; 
- DEQ (delivered ex-quay - entregue no cais): A responsabilidade do vendedor consiste em colocar a mercadoria à disposição do comprador, não desembaraçada para importação, no cais do porto de destino designado, a partir daí a responsabilidade é do comprador, inclusive no que diz respeito ao desembaraço aduaneiro de importação;

Existem incoterms que podem ser utilizados em qualquer modalidade de transporte, estando descritos abaixo:

- FCA (free carrier - transportador livre): O vendedor completa suas obrigações quando entrega a mercadoria, desembaraçada para a exportação, aos cuidados do transportador internacional indicado pelo comprador, no local determinado;

- CPT (carriage paid to - transporte pago até): O vendedor contrata e paga o frete para levar as mercadorias ao local de destino designado, sendo este responsável pelo desembaraço das mercadorias. A partir do momento em que as mercadorias são entregues à custódia do transportador, os riscos por perdas e danos se transferem do vendedor para o comprador, assim como possíveis custos adicionais que possam incorrer;

- CIP (carriage and insurance paid to - transporte e seguro pagos até): Nesta modalidade, as responsabilidades do vendedor são as mesmas descritas no CPT, acrescidas da contratação e pagamento do seguro até o destino;

- EXW (ex works - na fábrica): Este termo representa obrigação mínima para o vendedor, sendo que o comprador arca com todos os custos e riscos envolvidos em retirar a mercadoria do estabelecimento do vendedor. Este termo pode ser utilizado em qualquer modalidade de transporte;

- DAF (delivered at frontier - entregue até na fronteira): O vendedor deve entregar a mercadoria no ponto combinado na fronteira, porém antes da divisa aduaneira do país limítrofe, arcando com todos os custos e riscos até esse ponto, sendo a entrega é feita a bordo do veículo transportador, sem descarregar. O vendedor é responsável pelo desembaraço da exportação, mas não pelo desembaraço da importação;

- DDU (delivered duty unpaid - entregue direitos não pagos): O vendedor deve colocar a mercadoria à disposição do comprador, no ponto de destino designado, sem estar desembaraçada para importação e sem descarregamento do veículo transportador. O vendedor assume todas as despesas e riscos envolvidos até a entrega da mercadoria no local de destino designado, exceto quanto ao desembaraço de importação; 
- DDP (delivered duty paid - entregues direitos pagos): O vendedor entrega a mercadoria ao comprador, desembaraçada para importação no local de destino designado.

A Figura 4 representa de forma simplificada as responsabilidades do vendedor e do comprador no processo de importação e exportação.

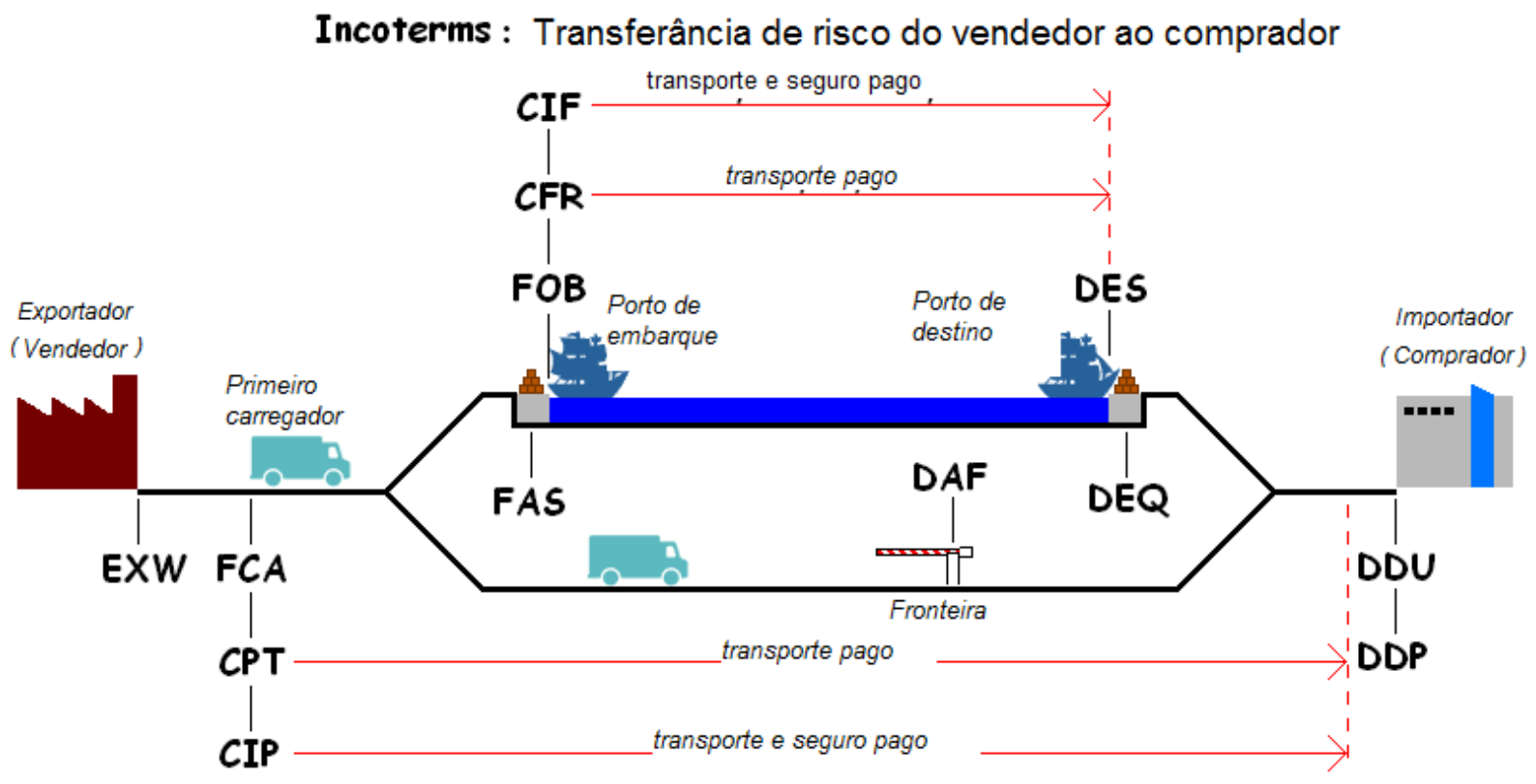

Figura 4 - Incoterms

Fonte: Universidade Corporativa Banco do Brasil

São os incoterms que estabelecem o maior grau de compromisso para o vendedor, na medida em que o mesmo assume todos os riscos e custos relativos ao transporte e entrega da mercadoria no local de destino designado.

\section{PROCEDIMENTOS METODOLÓGICOS}

De acordo com a proposição de Gil (2010) para a classificação da pesquisa, este estudo enquadra-se como exploratório quanto aos objetivos, quantitativo quanto à abordagem do problema e bibliográfico quanto aos procedimentos técnicos.

Por meio de uma revisão de literatura sistemática e coleta de dados baseada em informações disponíveis online, procurou-se efetuar um levantamento dos indicadores do transporte de carga (importação e exportação) na região dos Campos Gerais - PR.

Os dados buscados a partir do site do Ministério do Desenvolvimento, Indústria e 
Comércio Exterior, relatam a realidade local da região dos Campos Gerais referente à importação e exportação. Os dados coletados foram extraídos da guia "exportação", sendo que foram coletados dados para cada cidade pertencente à região dos Campos Gerais.

Os dados coletados do site do IBGE referem-se a informações pontuais (como a frota de veículos) referentes ao município de Ponta Grossa. As informações foram retiradas da guia "cidades".

As variáveis de análise averiguadas nesse estudo foram:

- Dados regionais por setor (indústria, comércio e serviços);

- Volume exportado por cada município dos Campos Gerais - PR;

- Produtos exportados pela região dos Campos Gerais - PR;

- Volume importado por cada município dos Campos Gerais - PR;

- Produtos importados pela região dos Campos Gerais - PR;

- Comparação dos municípios paranaenses com estrutura de um porto seco instalado;

- Frota de veículos do município de Ponta Grossa.

\section{RESULTADOS}

Diante das variáveis de análise supramencionadas, a configuração do cenário da região dos Campos Gerais, no Estado do Paraná, apresenta uma estrutura logística desenvolvida, pois o expressivo transporte de carga está abastecido principalmente por vias férreas e rodoviárias.

Seguindo o contexto apresentado, dados do Paraná apresentam que as exportações assumiram para a posição de $2^{\circ}$ lugar no Brasil em 2004, sendo que em 2003 era o $4^{\circ}$ colocado. De 2003 a 2004, as exportações paranaenses aumentaram 43\% no primeiro semestre. O Paraná exportou um total de US\$ 1 bilhão para a China, em um período de 8 meses (janeiro a setembro de 2004). A China representa o maior comprador dos produtos do Estado, sendo estes principalmente grãos e aves.

A soma das exportações dos municípios dos Campos Gerais no período de janeiro a setembro de 2004 representa $41 \%$ das exportações paranaenses, correspondendo a US\$ 1.677.473.385 em valores F.O.B.

Os setores econômicos que mais se destacam são o secundário, abrangendo alimentos, química, beneficiamento de madeira, fabricação de mobiliário, embalagens, bebidas, componentes automotivos, metalúrgicos, e comércio. 
O setor primário (agricultura e criação animal) é quatro vezes menor que o setor secundário. O setor de comércio destaca-se com veículos, peças e acessórios, ferragens, super e hipermercados, combustível, agropecuários, eletrodomésticos e lubrificantes. A Tabela 1 aponta o PIB de Ponta Grossa de acordo com o setor de atividade:

Tabela 1 - PIB de Ponta Grossa por setor de atividade

\begin{tabular}{llll}
\hline PIB de Ponta Grossa por atividade \\
\hline Ano & Agropecuária & Indústria & Serviço \\
1996 & $3 \%$ & $30 \%$ & $67 \%$ \\
2000 & $5 \%$ & $56 \%$ & $39 \%$ \\
\hline \multicolumn{4}{c}{ Fonte: IBGE, 2009.}
\end{tabular}

Percebe-se que de 1996 para 2000, houve uma inversão nos setores predominantes de atividade. O serviço possuía maior grau de atividade em 1996 e a indústria passa a exercer maior importância no PIB em 2000. Para caracterizar o potencial exportador dos Campos Gerais, realizou-se junto ao ministério do desenvolvimento um levantamento das exportações. A região exporta um total de US\$ 2.120.431.004.

Os municípios que contribuem com maior grau de significância para alavancar o volume de exportações da região são Ponta Grossa e Telêmaco Borba, respectivamente. A Tabela 2 apresenta o volume exportado pelos Campos Gerais em 2008:

Tabela 2 - Volume exportado pelos Campos Gerais - PR

\begin{tabular}{lll}
\hline Município & US\$ & $\begin{array}{l}\text { Representatividade (\%) } \\
\text { para os Campos Gerais }\end{array}$ \\
\hline Ponta Grossa & 1.619 .510 .532 & 76,38 \\
Telêmaco Borba & 349.660 .138 & 16,48 \\
Jaguariavaia & 50.069 .258 & 2,36 \\
Arapoti & 44.536 .806 & 2,10 \\
Castro & 21.524 .295 & 1,01 \\
Ventania & 18.587 .864 & 0,87 \\
Carambei & 9.038 .903 & 0,41 \\
Palmeira & 5.526 .120 & 0,26 \\
Tibagi & 1.296 .407 & 0,06 \\
São João do Triunfo & 406.113 & 0,02 \\
Ortigueira & 274.568 & 0,04 \\
TOTAL & $\mathbf{2 . 1 2 0 . 4 3 1 . 0 0 4}$ & $\mathbf{1 0 0}$ \\
\hline & Fonte: Ministério do desenvolvimento, 2008
\end{tabular}

Fonte: Ministério do desenvolvimento, 2008

Somente Ponta Grossa, exporta 76,38\% do volume exportado, ou seja, US\$ 1.619.510.532. Ponta Grossa e Telêmaco Borba enviam para o exterior um total de $93 \%$ do 
volume total. Ressalta-se que os municípios que não são todos os municípios pertencentes aos Campos Gerais que realizam atividades de exportação.

Os principais produtos exportados eram in natura, como grãos (principalmente de soja). Em 2004, os produtos de origem automobilística aumentam a sua participação nas exportações do Estado, representando 16,5\% do volume total. Para 2008, segue na Tabela 3, com os principais produtos exportados:

Tabela 3 - Principais produtos exportados pelos Campos Gerais

\begin{tabular}{ll}
\hline & $\begin{array}{l}\text { Representatividade } \\
(\%) \text { para os Campos } \\
\text { Groduto }\end{array}$ \\
\hline Bagaço e resíduos sólidos de soja & 19,55 \\
Pedaços e miudezas de frango & 17,68 \\
Óleo de soja bruto & 16,44 \\
Óleo de soja triturados & 4,84 \\
Óleo de soja em recipientes & 3,30 \\
Milho em grão & 2,74 \\
Carne de suíno congelada & 2,48 \\
Papéis de revestimento & 2,13 \\
Carnes de perus & 1,42 \\
\hline \multicolumn{2}{c}{ Fonte: Ministério do desenvolvimento, 2008 }
\end{tabular}

Os bagaços e resíduos sólidos de seja, os pedaços e miudezas de frango e o óleo de soja bruto são os produtos mais significativos para compor o volume exportado. Nas importações, o volume total é de US\$ 335.401.383. Apenas sete municípios que fazem parte dos Campos Gerais apresentam importações, conforme aponta a Tabela 4:

Tabela 4 - Volume importado pelos Campos Gerais - PR

\begin{tabular}{lll}
\hline Município & US\$ & $\begin{array}{l}\text { Representatividade } \\
(\%) \text { para os Campos } \\
\text { Gerais }\end{array}$ \\
\hline Ponta Grossa & 227.701 .450 & 67,89 \\
Telêmaco Borba & 45.473 .006 & 13,56 \\
Arapoti & 25.160 .109 & 7,50 \\
Jaguariaíva & 12.142 .971 & 3,65 \\
Carambeí & 9.503 .571 & 2,83 \\
Castro & 8.526 .743 & 2,54 \\
Palmeira & 6.717 .332 & 2,03 \\
TOTAL & $\mathbf{3 3 5 . 4 0 1 . 3 8 3}$ & $\mathbf{1 0 0}$ \\
\hline & Fonte: Ministério do desenvolvimento, 2008
\end{tabular}

O município de Ponta Grossa representa 67,89\% do volume importado pela região. Os principais produtos importados são compostos químicos, sendo estes utilizados para a fabricação de outros produtos, trigo e trigo com centeio e grãos de soja. Estes três produtos 
representam 60,44\% do volume total importado pelos campos gerais. A Tabela 5 apresenta a relação de todos os produtos importados, com sua respectiva equivalência no volume total.

Tabela 5 - Produtos importados pelos Campos Gerais

\begin{tabular}{lc}
\hline Município & $\begin{array}{c}\text { Representatividade (\%) } \\
\text { os Campos Gerais }\end{array}$ \\
\hline Composto químico & 42,34 \\
Trigo e trigo com centeio & 13,42 \\
Grãos de soja & 4,68 \\
Laminado (ferro e aço) & 1,46 \\
Feijão & 1,40 \\
Acessórios para tubos de alumínio & 1,31 \\
Grânulos, lascas e pó de mármore & 1,31 \\
Tubo de borracha vulcanizada & 1,27 \\
Papéis de celulose & 1,11 \\
Painéis e fibras de madeira & 1,05 \\
Outros & 31,65 \\
\hline
\end{tabular}

Fonte: Ministério do desenvolvimento, 2008

A região importa diversos produtos em quantidades muito pequenas, que somadas geram o valor de $31,65 \%$ das exportações, representadas na tabela por "outros". Em comparação com outros municípios com porto seco já instalado, Ponta Grossa apresenta um montante exportado elevado. A Tabela 6 apresenta o montante exportado por Ponta Grossa em comparação com os municípios que possuem porto seco instalado no Paraná.

Tabela 6 - Exportações de Ponta Grossa e municípios com porto seco

\begin{tabular}{lcc}
\hline Municípios & $\begin{array}{l}\text { Volume } \\
\text { (US\$) }\end{array}$ & exportado \\
\hline Ponta Grossa & 1.232 .272 .676 \\
Maringá & 455.809 .925 \\
Londrina & 366.001 .655 \\
Cascavel & 273.390 .308 \\
Foz do Iguaçu & 136.556 .637 \\
\hline \multicolumn{1}{c}{ Fonte: Ministério do desenvolvimento, 2008 }
\end{tabular}

O Paraná possui suas principais plataformas logísticas instaladas nas cidades de Maringá, Londrina, Cascavel e Fóz do Iguaçu. Somando os valores exportados por estas cidades, tem-se um total de US\$ 1.231.758.525, sendo que Ponta Grossa exportou US\$ 1.232.272.676. A diferença no valor exportado por Ponta Grossa e as cidades que contemplam plataforma logística é de US\$ 514.151. A Figura 5 aponta a descrição da frota em âmbito nacional e local. 


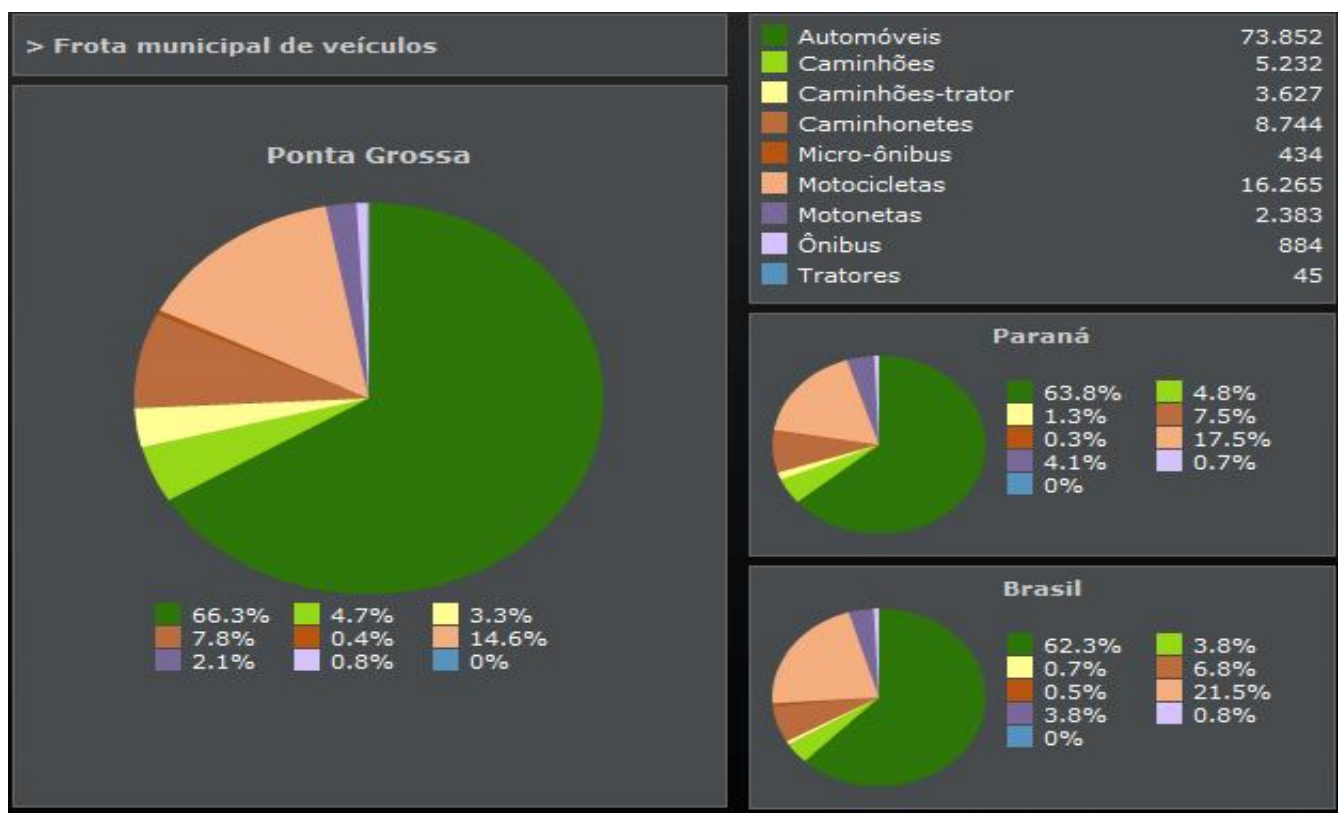

Figura 5: Frota de veículos

Fonte: IBGE, 2009.

Segundo análise do IBGE (2009), o município de Ponta Grossa apresenta 4,7\% dos seus veículos são destinados para o transporte de cargas, ou seja, composto por caminhões. Nesta mesma esfera, a média paranaense corresponde a 4,8\% da frota total, já o Brasil apresenta $3,8 \%$ da frota composta por veículos para transporte de cargas.

\section{CONSIDERAÇÕES FINAIS}

A intermodalidade é o transporte de mercadorias, do ponto de origem até o ponto de entrega, através de diferentes modais. A documentação é emitida de forma independente, uma para cada transportador, cada um assumindo a responsabilidade pelo seu transporte.

Todos os modais de transporte utilizam-se de terminais para o deslocamento das cargas. Os terminais são inevitavelmente a origem ou destino do tráfego, e, em alguns casos, o ponto onde a carga necessite de serviços como consolidação/desconsolidação para a distribuição da carga. Desta forma, eles podem ser considerados uma união de facilidades, onde se origina ou conclui o processo de transporte. No Brasil, somente no ano de 2006, o transporte rodoviário de carga movimentou 639 milhões de tonelada, em contra partida, o transporte ferroviário de carga deslocou 431 milhões de toneladas de produtos.

O posicionamento da cidade de Ponta Grossa, entre a rota ferroviária ligando o interior do Paraná ao Porto de Paranaguá e as regiões agrícolas paranaenses propiciam a instalação de indústrias de transformação, com atividades voltadas ao comércio exterior. Ponta Grossa apresenta denso entroncamento rodo-ferroviário, possibilitando o acesso de às demais regiões. 
Ponta Grossa comporta uma grande estrutura ferroviária que, através da mesma passam a produção agrícola de exportação via porto de Paranaguá.

O sistema de ferrovias do município é composto pela Rede Ferroviária Federal S.A, que tem suas linhas de direção para Curitiba, Porto de Paranaguá e Sul Brasileiro; Estrada de Ferro Central do Paraná, com linhas de direção para São Paulo (Ourinhos) e ao Norte do Estado Apucarana via Wenceslau Bráz).

Os dados apontam que o Estado do Paraná, de 2003 a 2004, apresentou um aumento de $43 \%$ no primeiro semestre no setor de exportações, sendo que o total exportado foi um total de US\$ 1 bilhão para a China, em um período de 8 meses (janeiro a setembro de 2004). O total das exportações dos municípios dos Campos Gerais no período de janeiro a setembro de 2004 representa 41\% das exportações paranaenses, correspondendo a US\$ 1.677 .473 .385 em valores F.O.B.

Para caracterizar o potencial exportador dos Campos Gerais, realizou-se junto ao ministério do desenvolvimento um levantamento das exportações. A região exporta um total de US\$ 2.120.431.004. Os municípios que contribuem com maior grau de significância para alavancar o volume de exportações da região são Ponta Grossa e Telêmaco Borba, respectivamente.

Nas importações, o volume total é de US\$ 335.401.383. O município de Ponta Grossa representa $67,89 \%$ do volume importado pela região. Os principais produtos importados são compostos químicos, sendo estes utilizados para a fabricação de outros produtos, trigo e trigo com centeio e grãos de soja. Estes três produtos representam 60,44\% do volume total importado pelos campos gerais.

\section{REFERÊNCIAS}

BALLOU, R. H. Gerenciamento da cadeia de suprimentos: planejamento, organização e logística empresarial. 4. ed. Porto Alegre: Bookman, 2001.

Logística empresarial: transportes, administração de materiais e distribuição física. São Paulo: Atlas, 1993.

BARRO, T.D. et al. Avaliação dos atrasos em transporte aéreo com um modelo DEA, Produção, v. 20, n. 4, p. 601-611, 2010.

BETARELLI JUNIOR, A. A.; BASTOS, S. Q. A.; PEROBELLI, F. S. Interações e encadeamentos setoriais com os modais de transporte: uma análise para diferentes destinos das exportações brasileiras, Economia Aplicada, v. 15, n. 2, p. 223,258, 2011. 
CHRISTOPHER, M. Logistics and supply chain management: strategies for reducing cost and improving service. London: Financial times, 2002.

CORREIA, T. C. V. D.; MELLO, J. C. C. B. S.; MEZA, L. A. Eficiência técnica das companhias aéreas brasileiras: um estudo com análise envoltória de dados e conjuntos nebulosos, Produção, 2011 (no prelo).

CUNHA, P. L. R.; PAULA, R. C.M.; FEITOSA, J. P. A. Polissacarídeos da biodiversidade brasileira: uma oportunidade de transformar conhecimento em valor econômico, Química Nova, v. 32, n. 3, p. 649-660, 2009.

DAMARIA, M. O operador de transporte multimodal como fator de otimização da logística, 2004, 86 f. Dissertação (Mestrado em Engenharia de Produção) - Programa de PósGraduação em Engenharia de Produção e sistemas, Universidade Federal de Santa Catarina, Florianópolis, 2004.

HADDAD, E. A. transporte, eficiência e desigualdade regional: avaliação com um modelo CGE para o Brasil. Pesquisa e Planejamento Econômico, v. 36, n. 3, p. 413-448, 2006.

IBGE - Instituto Brasileiro de Geografia e Estatística. Disponível: 〈www.ibge.org.br〉. Acesso em: 03 abr. 2009.

KEEDI, S. Transportes, utilização e seguros internacionais de carga: Prática e exercícios. 2 ed, São Paulo: 2003.

LIMA, G. B. et al. Consórcio de exportação como alternativa de pequenas e médias empresas: um estudo de caso na cadeia têxtil, Revista de Gestão USP, v. 15, n. 2, p. 1-18, 2008.

DESENVOLVIMENTO. Ministério do desenvolvimento, indústria e comércio exterior. Disponível: <http://www.mdic.gov.br/sitio/>. Acesso: 10 abr. 2009.

RODRIGUES, P. R. A. Introdução aos sistemas de transporte no Brasil e à logística internacional. 3. ed. São Paulo: Aduaneiras, 2003.

UNIVERSIDADE CORPORATIVA BANCO DO BRASIL. Treinamento em negócios internacionais. São Paulo: Banco do Brasil, 2006.

VASCONCELOS, E. Integrando P\&D à área de produção da empresa. In: Gerenciamento da Tecnologia: um instrumento para a competitividade empresarial. São Paulo: Editora Edgard Blucher Ltda. 1992. 